\title{
Celebrity Forum introduction: New faces, recurrent themes and research agendas
}

James Bennett, Royal Holloway, University of London

Hannah Hamad, Kings College, University of London

When we launched the forum section of the journal our hope was that it would stimulate not only timely interventions and provocations in the field, but act as a site of engagement with the field itself: directly responding to, questioning or building upon previous entries in the journal. In this issue, following on from Matthew Harris' (2013) use of Richard Howell's work on celebrity, saints and relics (2011), Ruth Penfold-Mounce revisits her earlier intervention in the forum (with David Beer 2010) to suggest how a neoliberal agenda in universities may actually further the status of a 'glossy topic' like celebrity studies. As UK universities are currently measuring, re-packaging and economically valuing the outcome of the Research Excellence Framework (REF2014), Penfold-Mounce's engagement with how neoliberalism affects research agendas is a timely reminder of the need to continue to promote risk and push the boundaries in our research.

Whilst many may dismiss media studies, let alone 'Celebrity Studies', as frivolous, the drive towards empirical data, impact and public engagement, alongside a rich and emergent set of methodologies that capture data from digital sources, which are increasingly seen as common place as they are cutting edge (with both descriptions attesting to the value of mining information from such platforms), sees Celebrity Studies well positioned in this climate. Our forthcoming issue on Celebrity Studies methodologies, arising out of our $2^{\text {nd }}$ biennial conference 
in 2014, demonstrates how our field excavates hidden depths that Penfold-Mounce points towards in her article here. From netnography to the television archive, and from audience research (see also our special issue 6.2 on audiences) to the epistemological and mnemonic, our methodologies special issue demonstrates the growing maturity and legitimacy in the field (see issue 6.3).

Elsewhere in the section we continue the theme of engaging with feminism and celebrity culture set out in issue 6.1 , mining the historical archive to produce richer understandings of the contemporary. Both Mara Dauphin and Tanya Horeck provide accounts of female celebrity that historicise current practices in presenting, re-presenting and debating depictions of female celebrity. In so doing, they both return to early Hollywood stardom to examine how earlier discourses around female beauty, spectacle and performance are re-circulated in current practices of online gossip and runway modeling. For Dauphin - engaging in the debate about 'unsexed', androgynous male or transgender models for womenswear fashion shows her exploration of these historical contours demonstrates how the current trend is neither new nor predicated on postmodern gender politics, 'but deeply embedded within a history of spectacular femininity'. Horeck interrogates the recent celebrity flashpoint that occurred concerning the altered facial appearance of Hollywood actor Renée Zellweger, following the star's widely mediated public appearance at the $21^{\text {st }}$ annual Women in Hollywood awards in October 2014: the scrutinization of which by audiences produced an explosion of affectively charged and gendered online discourse, subjecting Zellweger to intense pejorative abjectification. Horeck argues for this both as 'an exemplar of $21^{\text {st }}$ century digital stardom and the new kind of (inter) face-objects that stars have become', and as symptomatic of dominant 
discourses that emerge from the intersection of femininity and ageing in celebrity culture. In so doing she raises questions that resonate strongly with those posed by Deborah Jermyn in her 2012 special edition of this journal on 'Ageing, ageism and the lifespan of the female celebrity' in issue 3.1. The fact that this spectacle recently played out again with striking similarity in relation to Uma Thurman - another white female star of 1990s Hollywood, likewise now in her mid-40s, whose star power notably diminished upon entering her fifth decade - only serves to underscore the timeliness of Horeck's contribution to the continuing debate about the interaction of cosmetic surgery culture, social media, and aging female celebrity.

Finally, this issue also officially marks Hannah Hamad's co-editorship of the Forum section of the journal. Welcome! It's a pleasure to be working with her and the special issue on feminism and celebrity in issue 6.1 demonstrates the caliber of work in the field that we hope to continue to curate in this space. We hope the forum continues to act as a space to drive forward the field by taking risks, making interventions, provocations and empirical explorations. That continues to be our agenda!

\section{References}

Harris, M. 2013. The hologram of Tupac at Coachella and saints: the value of relics for devotees. Celebrity Studies, 4(2), 238-240.

Howells, R. 2011. Celebrities, saints and sinners: the photograph as holy relic. Celebrity studies, 2(2): 112-130. 